\title{
Total Oxidation of CO Using Cu \& Co Catalyst: Kinetic Study and Calcinations Effect
}

\author{
Gaurav Rattan*, Rajwant Kaur \\ Dr. S. S. Bhatnagar University Institute of Chemical Engineering \& Technology, Panjab \\ University, Chandigarh, India
}

Received: 30th July 2015; Revised: $7^{\text {th }}$ October 2015; Accepted: 8th October 2015

\begin{abstract}
The present study deals with the oxidation of $\mathrm{CO}$ using base metal catalysts. A series of copper cobalt with different mole ratios were prepared by wet-impregnation method calcined at $400{ }^{\circ} \mathrm{C}$ for $3 \mathrm{~h}$ for the oxidation of $\mathrm{CO}$. The mole ratios were varied from 1:1 to 1:5 by varying the weight of nitrates accordingly. It was found that 1:3 and 1:4 are active catalyst among the other prepared catalysts. Further, the two catalysts (1:3 \& 1:4) were prepared by co-precipitation and citric sol-gel methods in order to see the effect of preparation method. The results showed that the catalyst prepared by co-precipitation method is good in terms of activity for $\mathrm{CO}$ oxidation. The best selected catalyst was characterized by TGA/DSC and XRD. Kinetic study was also performed on the selected catalyst. (C) 2015 BCREC UNDIP. All rights reserved.
\end{abstract}

Keywords: CO Oxidation; Catalyst; Copper; Cobalt; Kinetics

How to Cite: Rattan, G., Kaur, R. (2015). Total Oxidation of CO Using Cu \& Co Catalyst: Kinetic Study and Calcinations Effect. Bulletin of Chemical Reaction Engineering \& Catalysis, 10 (3): 281-293. (doi:10.9767/bcrec.10.3.8875.281-293)

Permalink/DOI: http://dx.doi.org/10.9767/bcrec.10.3.8875.281-293

\section{Introduction}

The exploration and development of the catalyst for oxidation of $\mathrm{CO}$ has started earlier in the $19^{\text {th }}$ century during the World War II from now. Huge literature has been accumulated on the catalyst development. The catalysts used are noble metal catalysts [1,2], gold based catalysts [3-5], Transition base metal catalysts $[6,7]$ and provoskites. Due to urbanisation there is a rapid growth of vehicles around the globe and hence the air pollution associated with it. Carbon monoxide, hydrocarbons and oxides of nitrogen are some of the

* Corresponding Author.

E-mail: grattan@pu.ac.in (Gaurav Rattan)

Telp: +91-8288071498 main pollutants associated with the vehicular exhaust. Carbon monoxide is known a silent killer among all these pollutants. As CO combines with haemoglobin to make carboxyhemoglobin which reduces the oxygen carrying capacity of blood and affect the human body. Therefore the removal of $\mathrm{CO}$ from the vehicular exhaust is challenging task. Noble metal based catalysts are very successful and proved to be paramount in vehicular industry. They are used in vehicular industry controlling the vehicular exhaust from many decades. The noble metals used are Platinum, Palladium and Rhodium for the removal of harmful products to less harmful products. However in terms of economy and their rare availability challenges the researchers and scientist to make some other alternative to remove all these pollutants effectively. Further, the regulations and legis- 
lation limits adopted by government on the vehicles is very stringent and it will be more stringent in the near future. This motivates the researchers around the globe to explore and developed such catalyst which can do the same job as that of the noble metal.

Transition base metal catalysts $[8,9,16]$ have been studied in this regard from the past century and various techniques or catalyst have been developed which nearly do the same job as that of noble metal. One of the biggest advantages of base metal catalyst is there low cost and easy availability. Cobalt and copper are the two transition base metals [14, 20, 21] which are studied thoroughly for CO oxidation.

Xie et al. [15] Reported the preparation of $\mathrm{Co}_{3} \mathrm{O}_{4}$ nanorods by a morphology controlled method the resulting materials were steadily

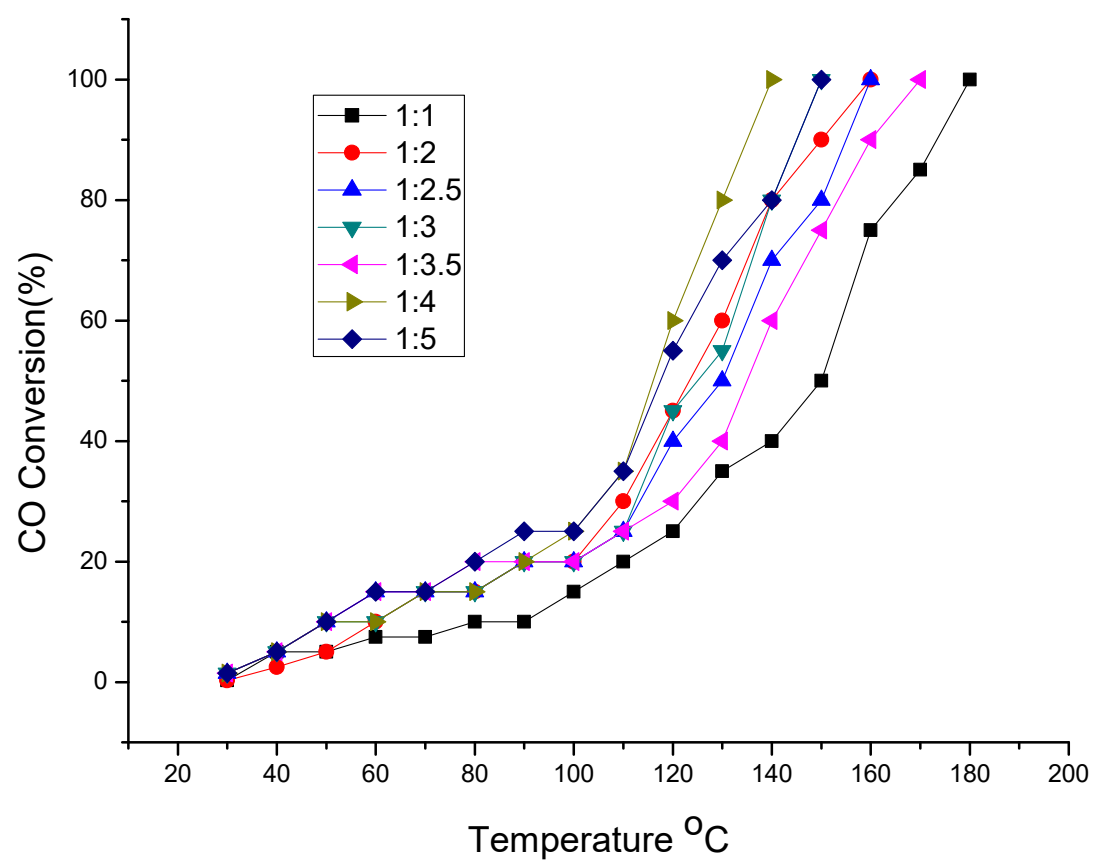

Figure 1. Catalytic activity of the catalyst by wet-impregnation method at different Cu:Co ratios

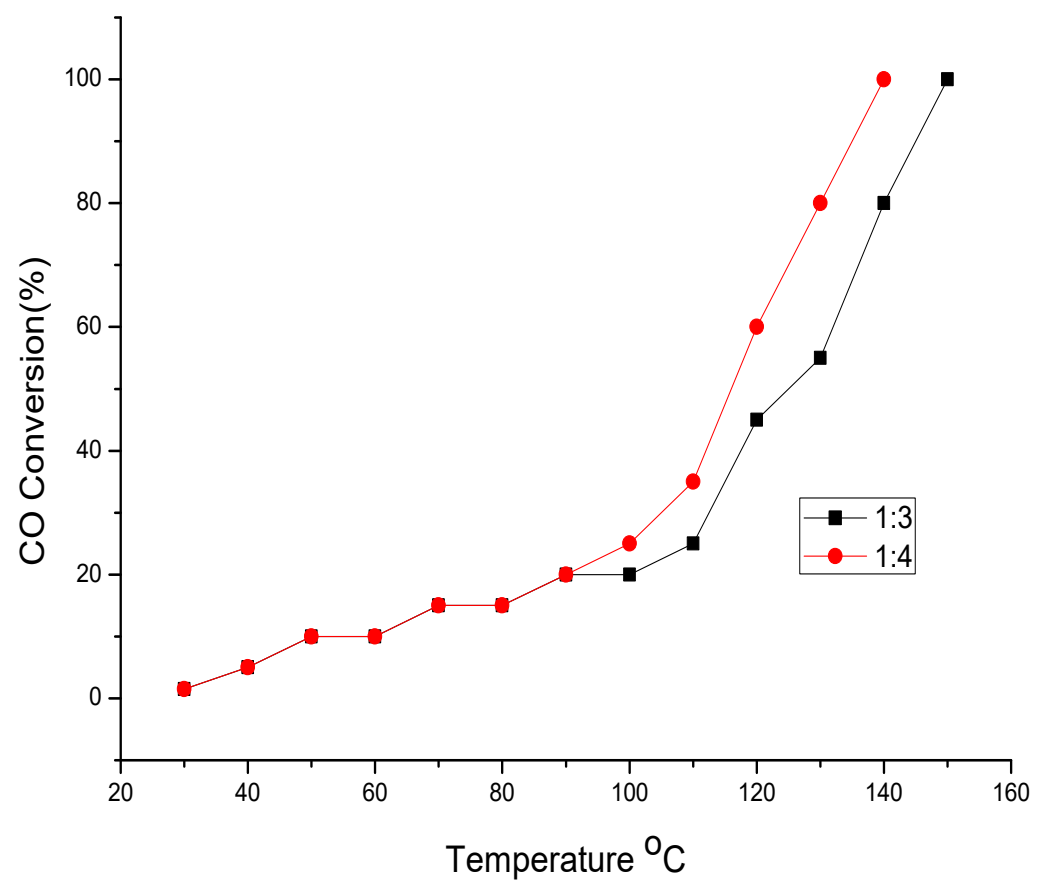

Figure 2. Comparison between mole ratio of $\mathrm{Cu}$ :Co 1:3 and 1:4 catalysts prepared by wet impregnation method 
active for $\mathrm{CO}$ oxidation at as low as $-77^{\circ} \mathrm{C}$. Feng et al. [15] reported that using facial pyrolysis method Mesoporous structured spinel $\mathrm{Co}_{3} \mathrm{O}_{4}$ could be fabricated and full $\mathrm{CO}$ conversion could be gotten at $-70^{\circ} \mathrm{C}$. Yung et al. [17] studied cobalt based catalyst supported on zirconia for CO oxidation and it was reported by them that $\mathrm{CO}$ oxidation can takes place at 135 ${ }^{\circ} \mathrm{C}$ temperature. Further the characterization of the catalyst was done by TGA/DSC, Laser Raman spectroscopy and XPS.

Recently Yuan et al. [18] studied CO oxidation on cobalt based catalyst. In this paper, mesoporous spinel-type complex oxides $\mathrm{MCo}_{2} \mathrm{O}_{4(4.5)}$ were prepared using one-pot strategy from the single phase multi-component oxalate precursors. The prepared material showed high surface area and excellent catalytic activity for low temperature $\mathrm{CO}$ oxidation. The catalytic experiments indicated that full CO conversion could be achieved at as low as $30^{\circ} \mathrm{C}$.

Copper is also studied for CO oxidation by numerous researchers [10, 19]. Guan et al. [10] studied copper-based catalyst and reported that complete conversion of $\mathrm{CO}$ takes place at $95{ }^{\circ} \mathrm{C}$. The effect of activation temperature and initial $\mathrm{CO}$ concentration on $\mathrm{CO}$ oxidation over $\mathrm{Cu} / \mathrm{TiO}_{2}$ were further investigated. XRD, TEM, XPSAES, $\mathrm{H}_{2}$-TPR and FTIR of $\mathrm{CO}$ adsorption were employed to characterize $\mathrm{Cu} / \mathrm{TiO}_{2}$ samples and the exact composition of $\mathrm{Cu} / \mathrm{TiO}_{2}$ prepared by photo-deposition was determined to be $\mathrm{Cu}$ $\mathrm{Cu}_{2} \mathrm{O} / \mathrm{TiO}_{2}$.
The combination of cobalt and copper is also depicted in many research articles [11-13]. However, these combination is not studied thoroughly. The combination of these two base metals can be studied thoroughly and interesting results could be there. Therefore, the present article deals with the combination of these two base metals catalyst and the optimisation were evaluated in terms of catalytic activity of $\mathrm{CO}$. The same catalyst was characterized by TGA/DSC and XRD. Moreover, the kinetic study has been done on the best selected catalyst.

\section{Experimental Section}

\subsection{Preparation of the Catalysts}

A number of cobalt and copper based catalysts was prepared using its nitrates salts with different mole ratios such as 1:1, 1:2, 1:2.5, 1:3, 1:3.5, 1:4, and 1:5. The entire chemicals used were of AR grade. The copper nitrate trihydrate and cobalt nitrate hexahydrate salts were used to prepare the catalyst for CO oxidation. The catalyst was prepared by three different methods, namely: (i) wet-impregnation method, (ii) sol-gel method, and (iii) coprecipitation method. The mole ratio of copper cobalt varies at different composition from 1:1 to $1: 5$. The prepared catalysts were stored in an air tight bottle (100-120 mesh size particles). Preparation methods of the catalyst are described as follow:

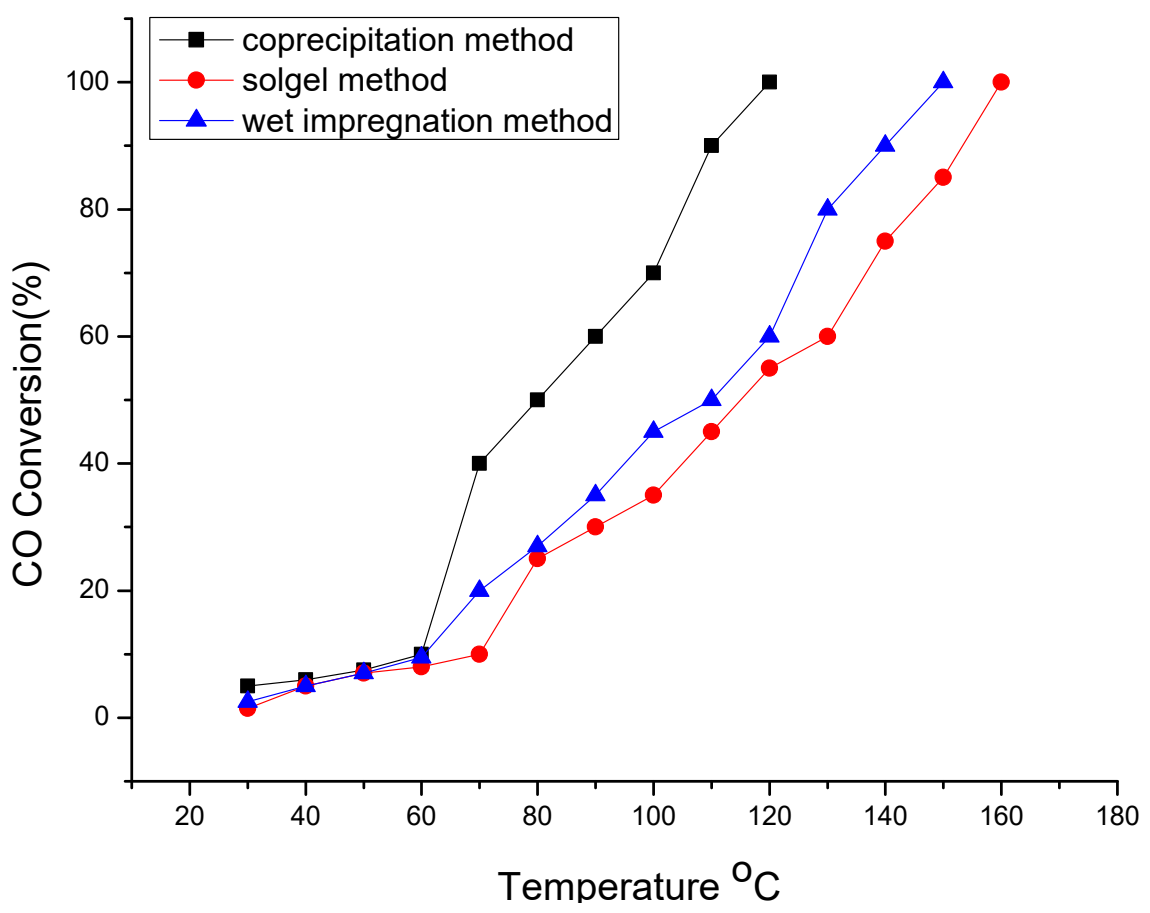

Figure 3. Effect of the preparation method on catalyst with mole ratio of $\mathrm{Cu}$ : $\mathrm{Co}$ 1:3 
Wet-impregnation method [12]: the stoichiometric amounts of copper cobalt nitrates salt were dissolved in distilled water under continuous stirring and heating at $80^{\circ} \mathrm{C}$ till dryness appear. Samples were further dried in an oven overnight at $100{ }^{\circ} \mathrm{C}$ and calcined in a muffle furnace at $400{ }^{\circ} \mathrm{C}$ for $3 \mathrm{~h}$.

Citric acid Sol-gel method [19]: metal nitrates were dissolved in distilled water according to required molar ratio and citric acid was added as a complexing agent with 1.3:1 ratio of acid to metals ions. Polyethylene glycol was added as an additive with $10 \%$ of the citric acid. The blended solution was mixed under continuous stirring at $80{ }^{\circ} \mathrm{C}$ till a gel was formed. This gel was dried overnight in oven at $100{ }^{\circ} \mathrm{C}$ and calcined in the muffle furnace at $400{ }^{\circ} \mathrm{C}$ for $3 \mathrm{~h}$.

Co-precipitation method [14]: the solution of metal nitrates was slowly added to the solution of sodium carbonate in distilled water under continuous stirring by maintaining the $\mathrm{pH}$ 10. After some time precipitates formed were filtered with Whatman's filter paper and washed several times with distilled water and dried in an oven overnight at $100{ }^{\circ} \mathrm{C}$. After drying, the sample was calcined in muffle furnace at $400{ }^{\circ} \mathrm{C}$ for $3 \mathrm{~h}$.

\subsection{Catalytic Activity Measurements}

The catalytic activity was measured in tubular packed bed reactor at atmospheric pressure. $100 \mathrm{mg}$ of the prepared catalyst was diluted or mixed with the $5 \mathrm{~mL}$ of alumina [22]. The mixture prepared was placed in fixed bed down flow tubular reactor by making bed of glass wool. The reactor was placed vertically in a open-split furnace. The reactant consist of $2 \%$ of $\mathrm{CO}$ was mixed with air having a total flow rate of $100 \mathrm{~mL} / \mathrm{min}$. The flow rate of $\mathrm{CO}$ and air were monitored with the help of digital flow meters. The air feed was made free of moisture and $\mathrm{CO}_{2}$ by passing it through $\mathrm{CaO}$ and $\mathrm{KOH}$

Table 1. Light off temperatures of $\mathrm{Cu}$ :Co 1:3 prepared by different methods

\begin{tabular}{lccc}
\hline \multirow{2}{*}{ Preparation method } & \multicolumn{3}{c}{ Temperature $\left({ }^{\circ} \mathrm{C}\right)$} \\
\cline { 2 - 4 } & $\mathrm{T}_{10 \%}$ & $\mathrm{~T}_{50 \%}$ & $\mathrm{~T}_{100 \%}$ \\
\hline $\begin{array}{l}\text { Co-precipitation } \\
\text { method }\end{array}$ & 40 & 80 & 120 \\
$\begin{array}{l}\text { Sol-gel method } \\
\begin{array}{l}\text { wet-impregnation } \\
\text { method }\end{array}\end{array}$ & 50 & 120 & 160 \\
\hline
\end{tabular}

pellet. The steady state activity was measured from room temperature to $250{ }^{\circ} \mathrm{C}$. The catalytic experiments were carried out under steady state conditions. The reactants and products were analysed under steady state conditions for $\mathrm{CO}$ and $\mathrm{CO}_{2}$ with the help of Gas Chromatograph. The catalytic activity was expressed by the conversion of $\mathrm{CO}$ calculated by Equation (1).

$X_{C O}=\frac{\left(C_{C O, \text { in }}-C_{C O, \text { out }}\right)}{C_{C O, \text { in }}}$

\section{Results and Discussions}

\subsection{Catalysts Prepared by Wet Impregna- tion Method}

The catalytic activity of the catalyst prepared by wet-impregnation method is shown in figure 1. The mole ratio of $\mathrm{Cu}$ :Co are 1:1, 1:2, $1: 2.5,1: 3,1: 3.5,1: 4$, and 1:5. The various mole ratio of copper cobalt gives the $\mathrm{CO}$ conversion at different temperature. It is clearly shown in the graph that the catalytic activity increase from mole ratio $\mathrm{Cu}$ :Co of $1: 1$ to $1: 5$ for most of the cases. It is clearly visible in figure that the catalyst having mole ratio of $\mathrm{Cu}: \mathrm{Co}$ of $1: 3$ and 1:4 respectively gives better result in terms of activity. The mole ratio of $\mathrm{Cu}: \mathrm{Co}$ of 1:3 and 1:4 gives $100 \% \mathrm{CO}$ oxidation at minimum temperature. Catalyst having mole ratio of 1:3 gives $100 \% \mathrm{CO}$ conversion at $150{ }^{\circ} \mathrm{C}$ and at $1: 4$ gives $100 \% \mathrm{CO}$ conversion at $140{ }^{\circ} \mathrm{C}$ which is the minimum temperature as compared to the other prepared catalysts. In order to see the Conversion versus temperature of mole ratio of copper cobalt 1:3 and 1:4 clearly shown in Figure 2.

\subsection{Effect of The Preparation Method on Catalytic Activity}

From the previous result of the catalyst prepared by wet-impregnation method find that

Table 2. Light off temperatures of $\mathrm{Cu}$ :Co of $1: 4$ prepared by different methods

\begin{tabular}{lccc}
\hline \multirow{2}{*}{ Preparation method } & \multicolumn{3}{c}{ Temperature $\left(^{\circ} \mathrm{C}\right)$} \\
\cline { 2 - 4 } & $\mathrm{T}_{10 \%}$ & $\mathrm{~T}_{50 \%}$ & $\mathrm{~T}_{100 \%}$ \\
\hline $\begin{array}{l}\text { Co-precipitation } \\
\text { method }\end{array}$ & 40 & 80 & 110 \\
$\begin{array}{l}\text { Sol-gel method } \\
\begin{array}{l}\text { wet-impregnation } \\
\text { method }\end{array}\end{array}$ & 50 & 100 & 130 \\
\hline
\end{tabular}


1:3 and 1:4 is best active catalyst. To see the effect of preparation methods the mole ratio of copper cobalt catalyst were prepared by other two methods which are sol-gel and coprecipitation method.

\subsubsection{Catalysts Having Mole Ratio of $\mathrm{Cu}: \mathrm{Co}=1: 3$}

Co-precipitation method gives best result as compared to the catalyst prepared by other method. The catalyst prepared by coprecipitation method gives 100\% CO conversion at $120{ }^{\circ} \mathrm{C}$. However the catalyst prepared by sol-gel method is poorest in terms of activity. Table1. gives light off temperature of catalyst having $\mathrm{Cu}: \mathrm{Co}=1: 3$.

3.2.2. Catalytic Activity of Catalysts with Molar Ratio of $\mathrm{Cu}: \mathrm{Co}=1: 4$

In this, catalyst with mole ratio 1:4 prepared by co-precipitation method gives good result as compared to the other methods. The catalyst prepared by co-precipitation method gives $100 \% \mathrm{CO}$ conversion at $110{ }^{\circ} \mathrm{C}$ which is the lowest from the other catalysts. While the catalyst prepared by sol-gel and wet- impregnation method showed relatively low active for $\mathrm{CO}$ oxidation and complete $\mathrm{CO}$ conversion achieved at $130{ }^{\circ} \mathrm{C}$ and $140{ }^{\circ} \mathrm{C}$ respectively. Table 2 gives light off temperature of catalyst having $\mathrm{Cu}: \mathrm{Co}=1: 4$. From Figure 5, it is clearly shown that the catalyst prepared by coprecipitation $(\mathrm{Cu}: \mathrm{Co}=1: 4)$ method is the best ac- tive catalyst for $\mathrm{CO}$ oxidation i.e. $\mathrm{T}_{100 \%}=110^{\circ} \mathrm{C}$. For light off temperature of $\mathrm{Cu}: \mathrm{Co}=1: 3$ and 1:4 is shown in Table 3.

\subsubsection{Effect of Calcination Temperature}

Effect of the calcination temperature on the best active catalyst is studied by varying the calcinations temperature, i.e. from 300 to 500 ${ }^{\circ} \mathrm{C}$. The calcined catalysts were studied for $\mathrm{CO}$ oxidation and the results are obtained in Figure 6. It can be seen from the figure that the catalyst calcined at $400{ }^{\circ} \mathrm{C}$ exhibited the highest activity and achieved 100\% CO conversion at $110{ }^{\circ} \mathrm{C}$. Calcination of the catalysts at higher temperature caused sintering, which led to a decrease in the surface area and decrease in catalytic activity [22].

\subsection{Characterization}

\subsubsection{Thermo Gravimetric Analysis (TGA/DSC)}

In the present work TGA was carried out for uncalcined sample prepared by co-precipitation

Table 3. Light off temperatures of $\mathrm{Cu}$ :Co of $1: 3$ and 1:4 prepared by co-precipitation method

\begin{tabular}{cccc}
\hline \multirow{2}{*}{$\begin{array}{c}\text { Co-precipitation } \\
\text { method }\end{array}$} & \multicolumn{3}{c}{ Temperature $\left({ }^{\circ} \mathrm{C}\right)$} \\
\cline { 2 - 4 } & $\mathrm{T}_{10 \%}$ & $\mathrm{~T}_{50 \%}$ & $\mathrm{~T}_{100 \%}$ \\
\hline $1: 3$ & 40 & 80 & 120 \\
$1: 4$ & 40 & 70 & 110 \\
\hline
\end{tabular}

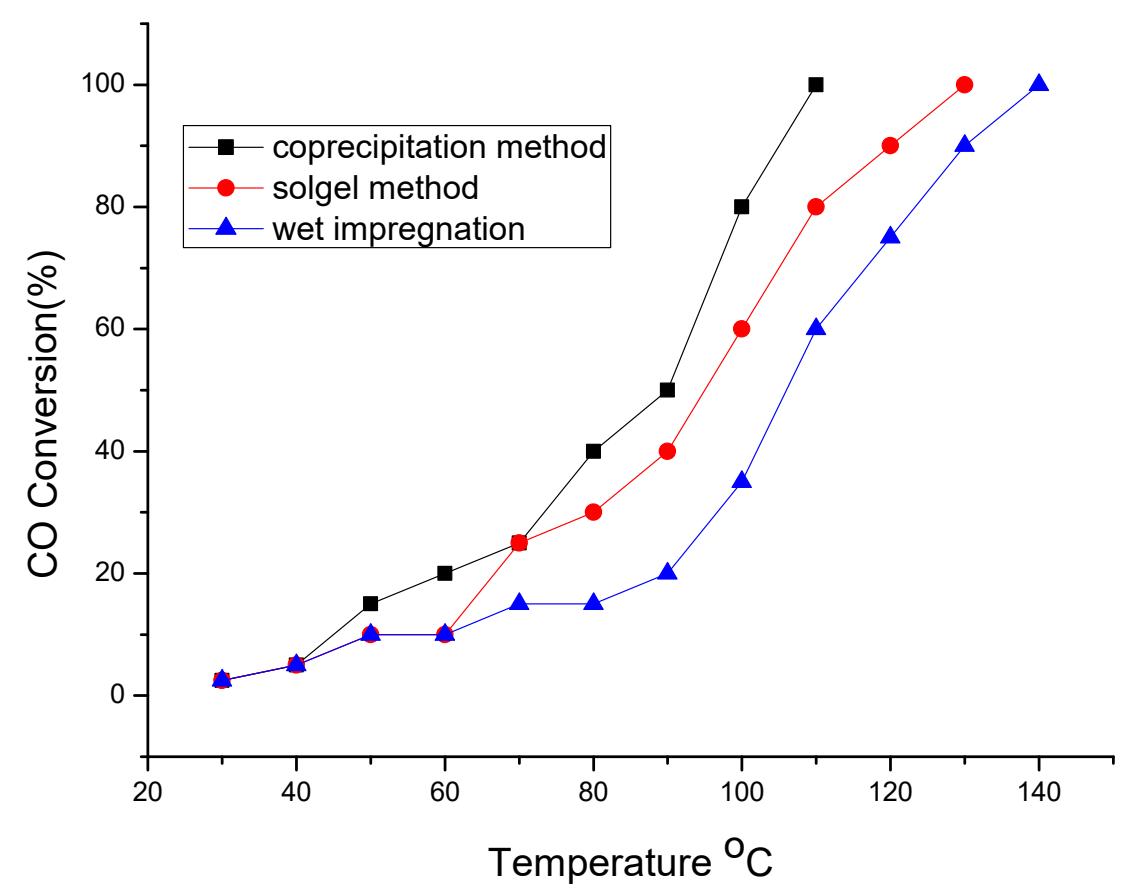

Figure 4. Effect on preparation method on mole ratio of $\mathrm{Cu}$ :Co 1:4 
method. Thermo gravimetric analysis (TGA) is the most widely used thermal method based on the measurement of mass loss of material as a function of temperature. In thermogravimetry a continuous graph of mass change against temperature is obtained when a substance is heated at uniform rate or kept at constant tem- perature. A plot of mass change versus temperature $(T)$ is referred to as the thermo gravimetric curve (TG curve). For the TG curve, we generally plot mass $(m)$ decreasing downwards on the $y$ axis (ordinate), and temperature $(T)$ increasing to the right on the $\mathrm{x}$ axis (abscissa) as shown in Figures 7 and 8.

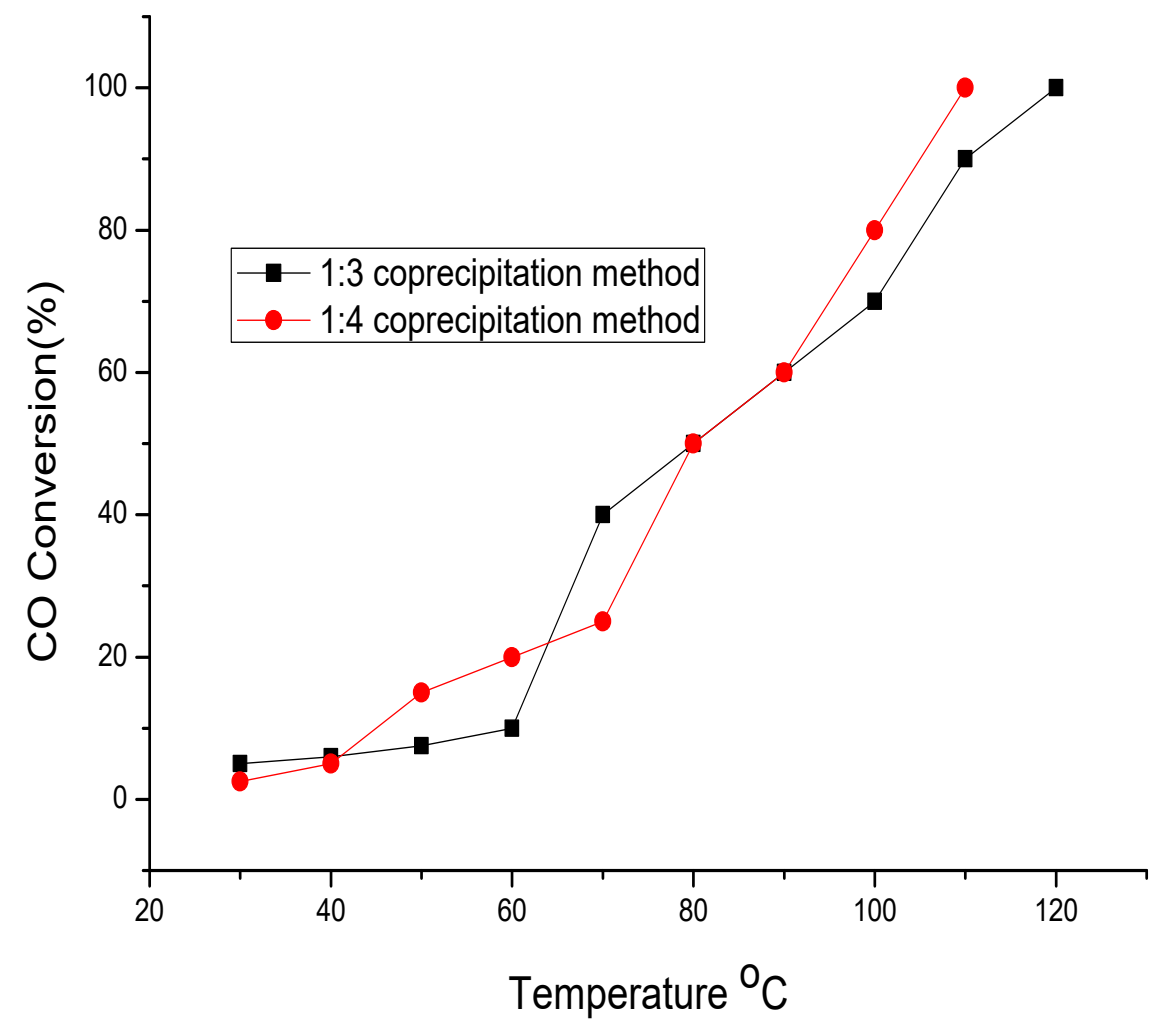

Figure 5. Comparison between mole ratio of $\mathrm{Cu}$ : $\mathrm{Co}$ of 1:3 and 1:4 prepared by co precipitation method

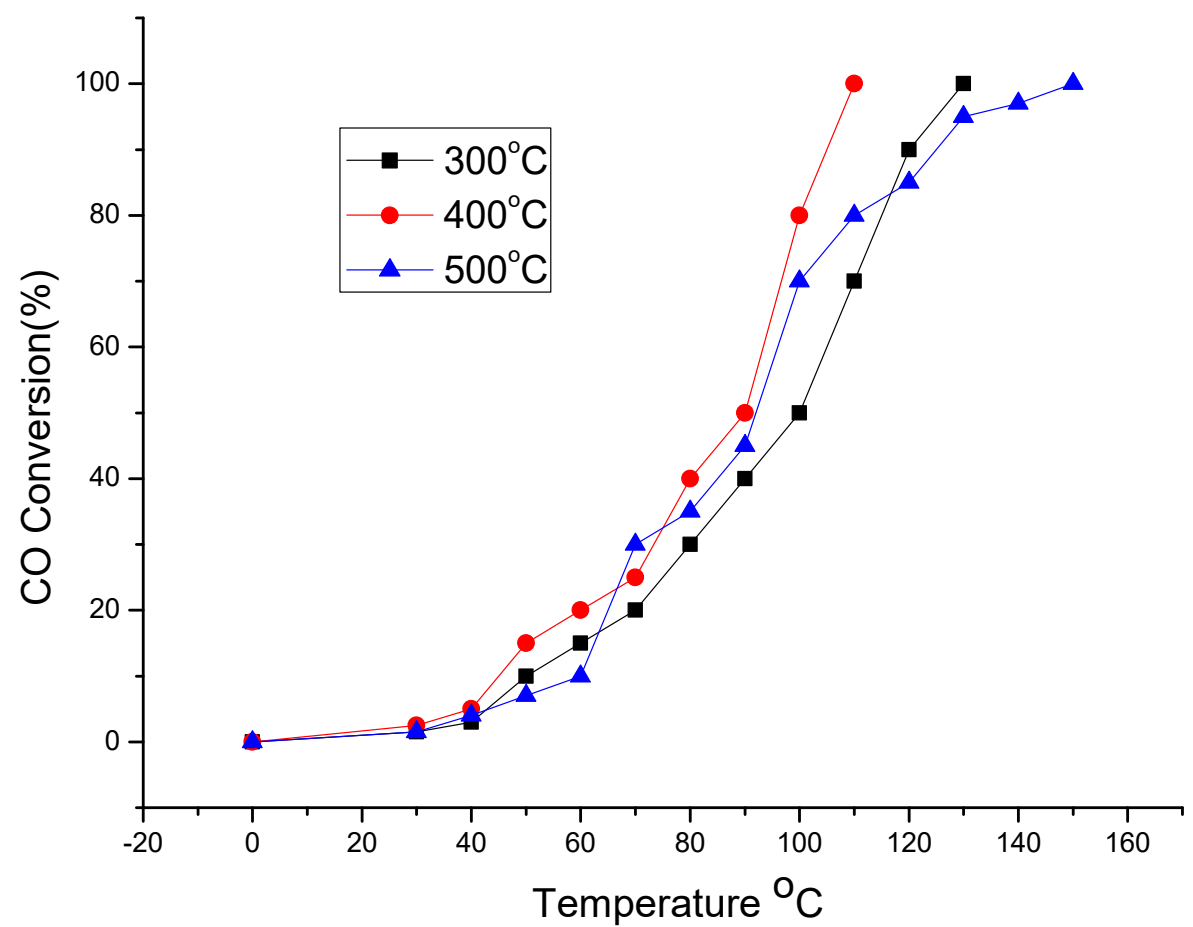

Figure 6. Effect of the calcinations temperature on mole ratio of $\mathrm{Cu}: \mathrm{Co} 1: 4$ 


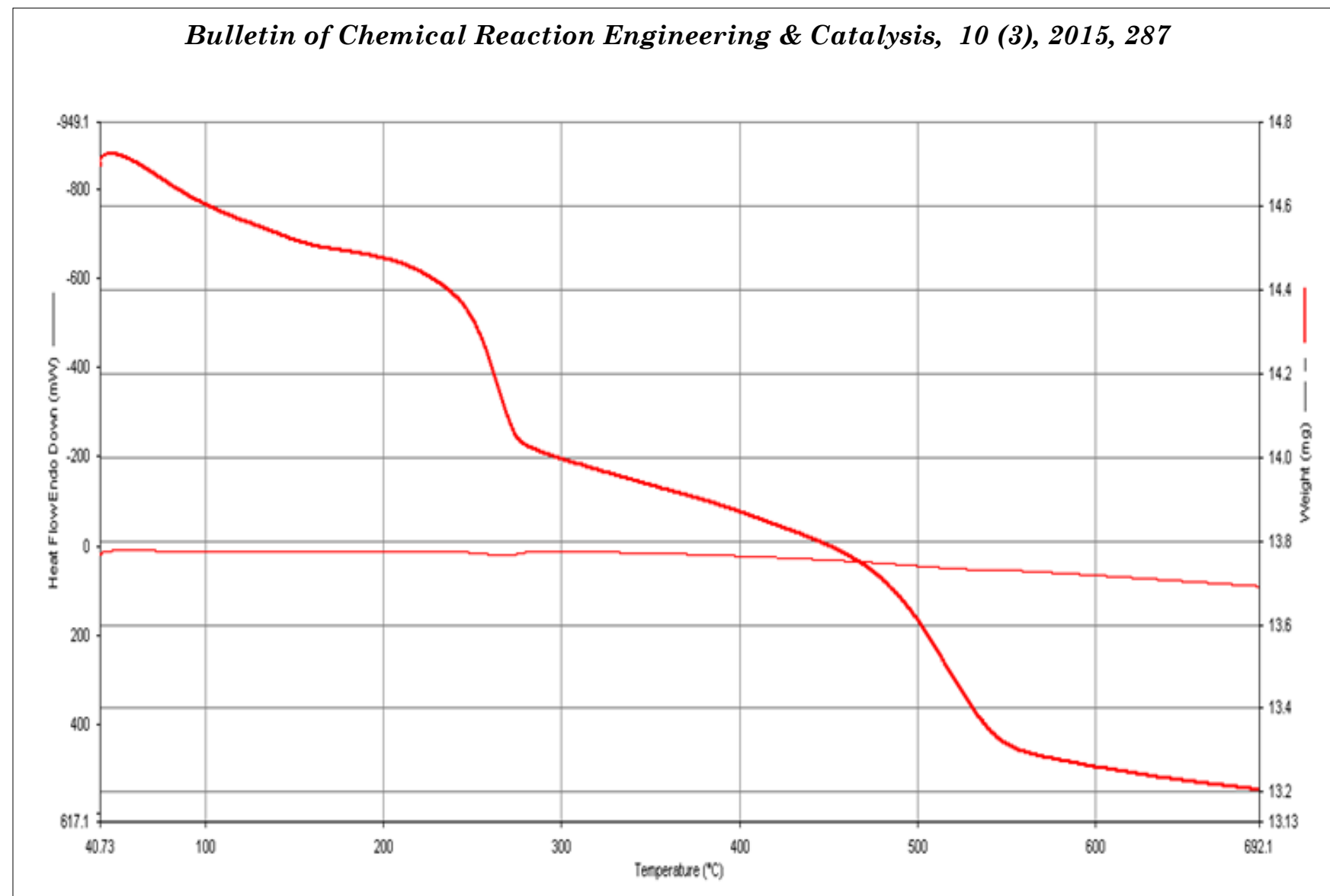

Figure 7. TGA/DSC curve of the catalysts having molar ratio $\mathrm{Cu}$ :Co of $1: 3$ prepared by coprecipitation method

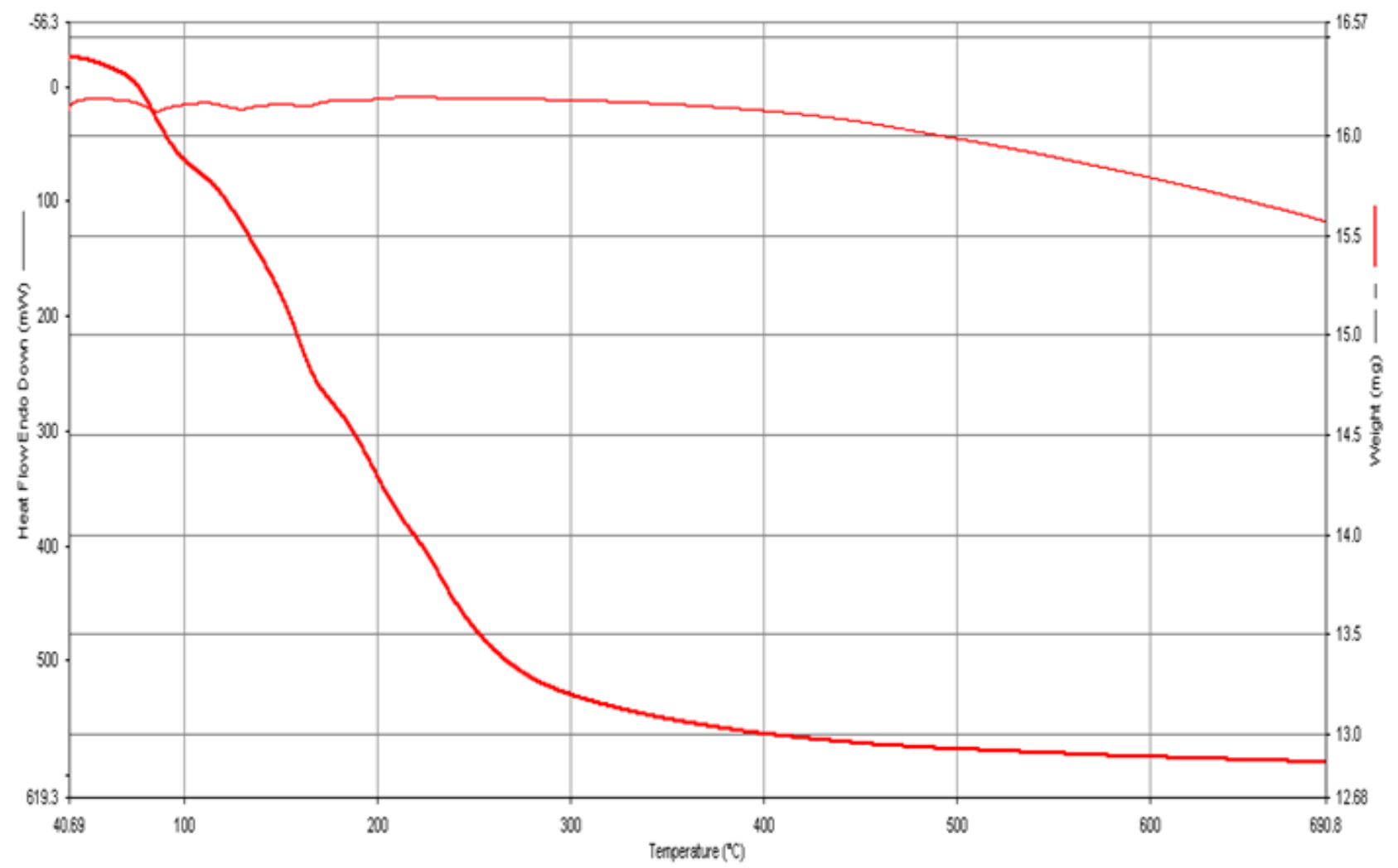

Figure 8. TGA/DSC curve of the catalysts having molar ration $\mathrm{Cu}$ :Co of 1:4 prepared by coprecipitation method 
TGA/DSC curve of the catalysts having molar ratio of copper cobalt 1:3 and 1:4 prepared by co-precipitation method is shown in Figures 7 and 8, respectively. In the Figure 7 temperature range of 90 to $200{ }^{\circ} \mathrm{C}$ depicts the moisture content loss and the main weight lost in between $300-600{ }^{\circ} \mathrm{C}$. This may be due to the decomposition of the various nitrates present in the catalyst. However there is a sharp decrease in the weight of the catalyst from 100 to $400{ }^{\circ} \mathrm{C}$ in Figure 8. The moisture content may be attributed to the temperature of 100 to $200{ }^{\circ} \mathrm{C}$. However the rest is because of the decomposition of metal ions and nitrates present in the catalyst. The total weight loss is $20-25 \%$ as shown in figure.

\subsubsection{X-Rays Diffraction}

X-Ray diffraction (XRD) of the catalyst samples was carried out to indentify the phases and oxidation states present in the catalysts. XRD pattern was recorded in X'PERT PRO diffractometer using $\mathrm{CuKa}$ radiation source with operating current and operation voltage were $40 \mathrm{~mA}$ and $45 \mathrm{KV}$ respectively. The scanning range $2 \theta$ was $5.00-99.98^{\circ}$ with divergence slit of $0.8709^{\circ}$. The continuous scanning was done with step size of $0.0170^{\circ}$ and with scan step time of $30.36 \mathrm{~s}$. The XRD pattern of the prepared mole ratio of copper cobalt catalysts $1: 3$ and $1: 4$ calcined at $400{ }^{\circ} \mathrm{C}$. In the Figure 9 the representative XRD pattern in which peaks at $2 \theta$ of $31.245,36.758,38.44,44.465,59.165$, and 64.562 shows different lattice planes. Further the strong peak at 38.44 attributed to the cobalt species and rest of the peaks are due to the formation of oxides. The diffraction peaks of catalyst showed that the catalyst is almost amorphous. The broad diffraction peaks are due to the formation of small crystallites.

Table 4. Optimisation of calcination temperature $\mathrm{Cu}$ :Co of $1: 4$ between $300-500{ }^{\circ} \mathrm{C}$

\begin{tabular}{cccc}
\hline Calcination Temperature $(\mathrm{oC})$ & $\mathrm{T}_{10 \%}$ & $\mathrm{~T}_{50 \%}$ & $\mathrm{~T}_{100 \%}$ \\
\hline 300 & 50 & 90 & 130 \\
400 & 40 & 80 & 110 \\
500 & 60 & 100 & 160 \\
\hline
\end{tabular}

Table 5. Space velocity of $100 \mathrm{mg}$ catalyst

\begin{tabular}{cccc}
\hline Sr.no & CO (ml/min) & Air $(\mathrm{ml} / \mathrm{min})$ & $W / F_{\text {CO }}($ gcat.h/gmol) \\
\hline 1 & 4 & 96 & 10.05 \\
2 & 3 & 97 & 13.40 \\
3 & 2 & 98 & 20.11 \\
4 & 1 & 99 & 40.22 \\
\hline
\end{tabular}

Table 6. Space velocity of $200 \mathrm{mg}$ catalyst

\begin{tabular}{cccc}
\hline Sr.no & CO (ml/min) & Air $(\mathrm{ml} / \mathrm{min})$ & W/F \\
\hline 1 & 4 & 96 & 20.11 \\
2 & 3 & 97 & 26.66 \\
3 & 2 & 98 & 40.41 \\
4 & 1 & 99 & 81.27 \\
\hline
\end{tabular}

Table 7. CO conversion at different space velocity

\begin{tabular}{ccccc}
\hline W/F & \multicolumn{4}{c}{ Conversion Temperature $\left({ }^{\circ} \mathrm{C}\right)$} \\
\cline { 2 - 5 } (gcat.h/gmol) & 30 & 40 & 50 & 60 \\
\hline 10.05 & 0.016 & 0.027 & 0.042 & 0.050 \\
13.40 & 0.025 & 0.040 & 0.055 & 0.070 \\
20.11 & 0.041 & 0.057 & 0.072 & 0.085 \\
40.22 & 0.058 & 0.075 & 0.090 & 0.100 \\
\hline
\end{tabular}


Bulletin of Chemical Reaction Engineering \& Catalysis, 10 (3), 2015, 289

Table 8. Fractional conversion of $\mathrm{CO}\left(x_{C O}\right)$ vs $W / F_{C O}$ at different temperature

\begin{tabular}{cccc}
\hline Temperature $\left({ }^{\circ} \mathrm{C}\right)$ & $x_{C O}$ & $\ln \mathrm{r}_{\text {obs }}$ & $\ln C_{c o}$ \\
\hline 30 & 0.016 & -6.14 & -10.10 \\
30 & 0.025 & -6.16 & -10.11 \\
30 & 0.041 & -6.2 & -10.13 \\
30 & 0.058 & -6.24 & -10.15 \\
40 & 0.027 & -5.71 & -10.11 \\
40 & 0.040 & -5.75 & -10.13 \\
40 & 0.057 & -5.78 & -10.15 \\
40 & 0.075 & -5.79 & -10.16 \\
50 & 0.042 & -5.49 & -10.13 \\
50 & 0.055 & -5.495 & -10.14 \\
50 & 0.072 & -5.53 & -10.16 \\
50 & 0.090 & -5.55 & -10.18 \\
60 & 0.050 & -5.18 & -10.14 \\
60 & 0.070 & -5.22 & -10.16 \\
60 & 0.085 & -5.224 & -10.18 \\
60 & 0.100 & -5.27 & -10.19 \\
\hline
\end{tabular}

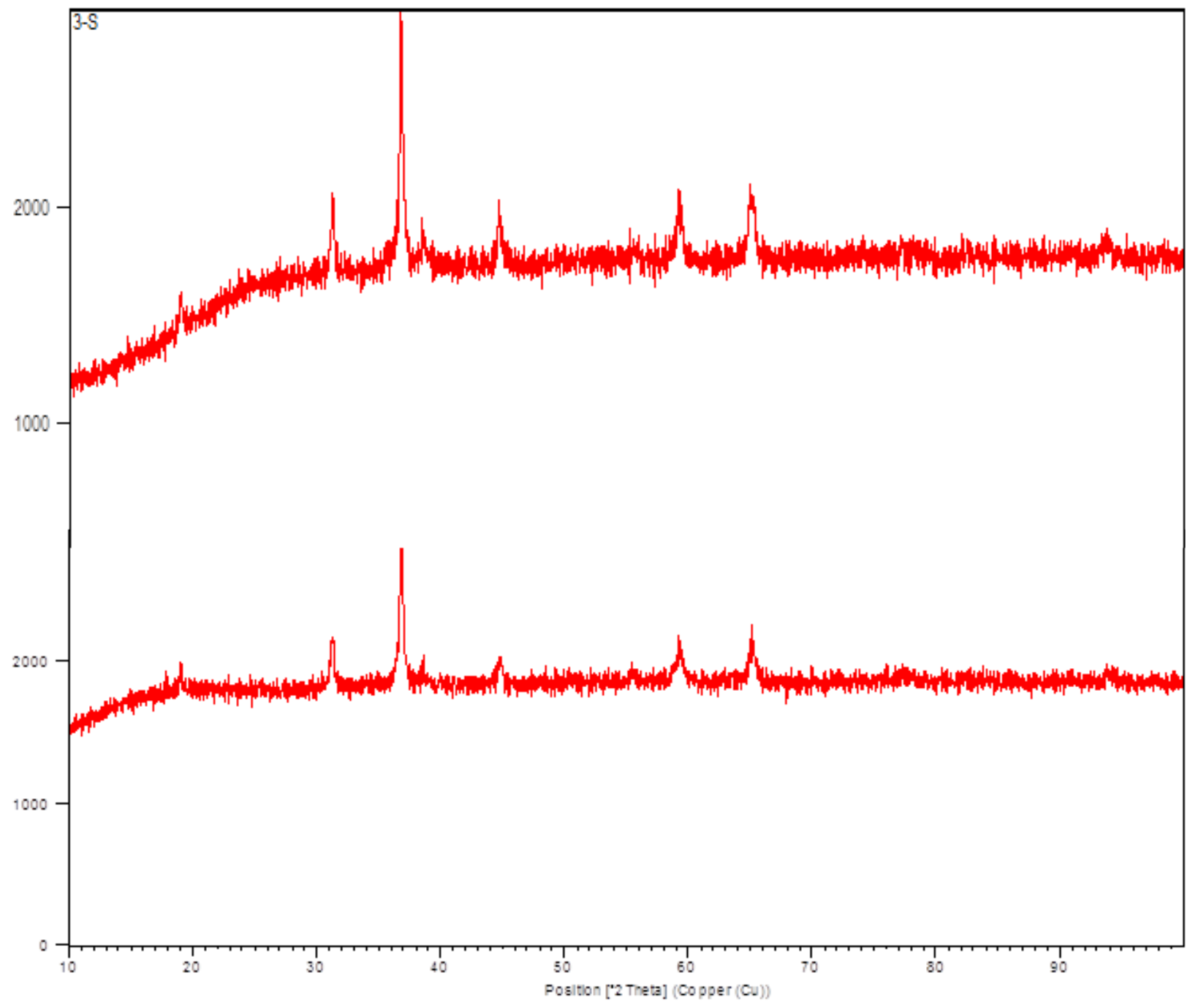

Figure 9. XRD pattern of catalysts having molar ratio of $\mathrm{Cu}$ :Co of 1:3 and 1:4 


\subsection{Kinetic Study}

Chemical kinetics is also known as reaction kinetics, reaction kinetics is the study of rates of chemical processes. Chemical kinetics include investigation of how different experimental conditions can influence the speed of a chemical reaction and the yield information about the reaction's mechanism and transition states, as well as the construction models that can describe the characteristics of the chemical reaction. Chemical kinetics deals with the ex- perimental determination of reaction rates from which rate laws and rate constants are derived. Relatively simple rate laws exist for zero order reactions, first order reactions, and second order reactions, and can be derived from others. The activation energy for a reaction is experimentally determined through the Arrhenius equation; the main factors that influence the reaction rate include the physical state of the reactants, the concentrations of the reactants, the temperature at which reaction occurs.

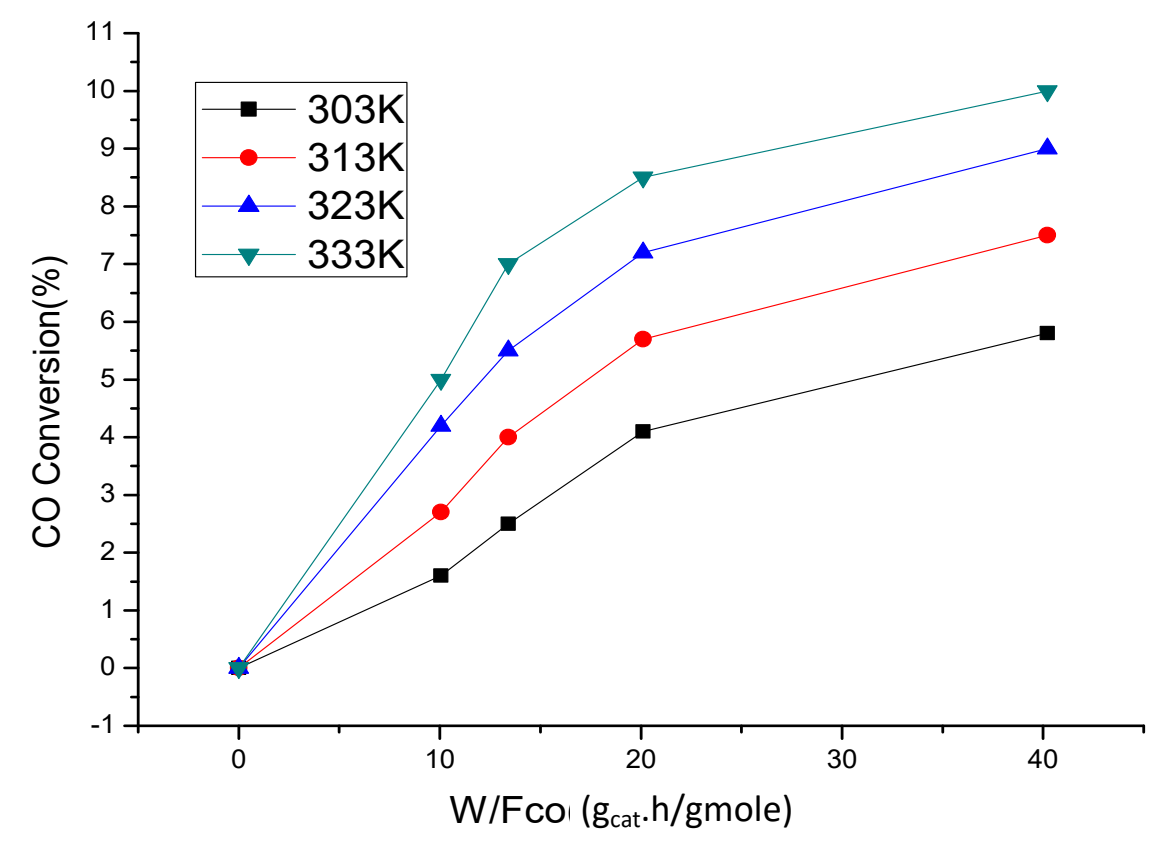

Figure 10. Plot of CO conversion vs. W/Fco at different temperature

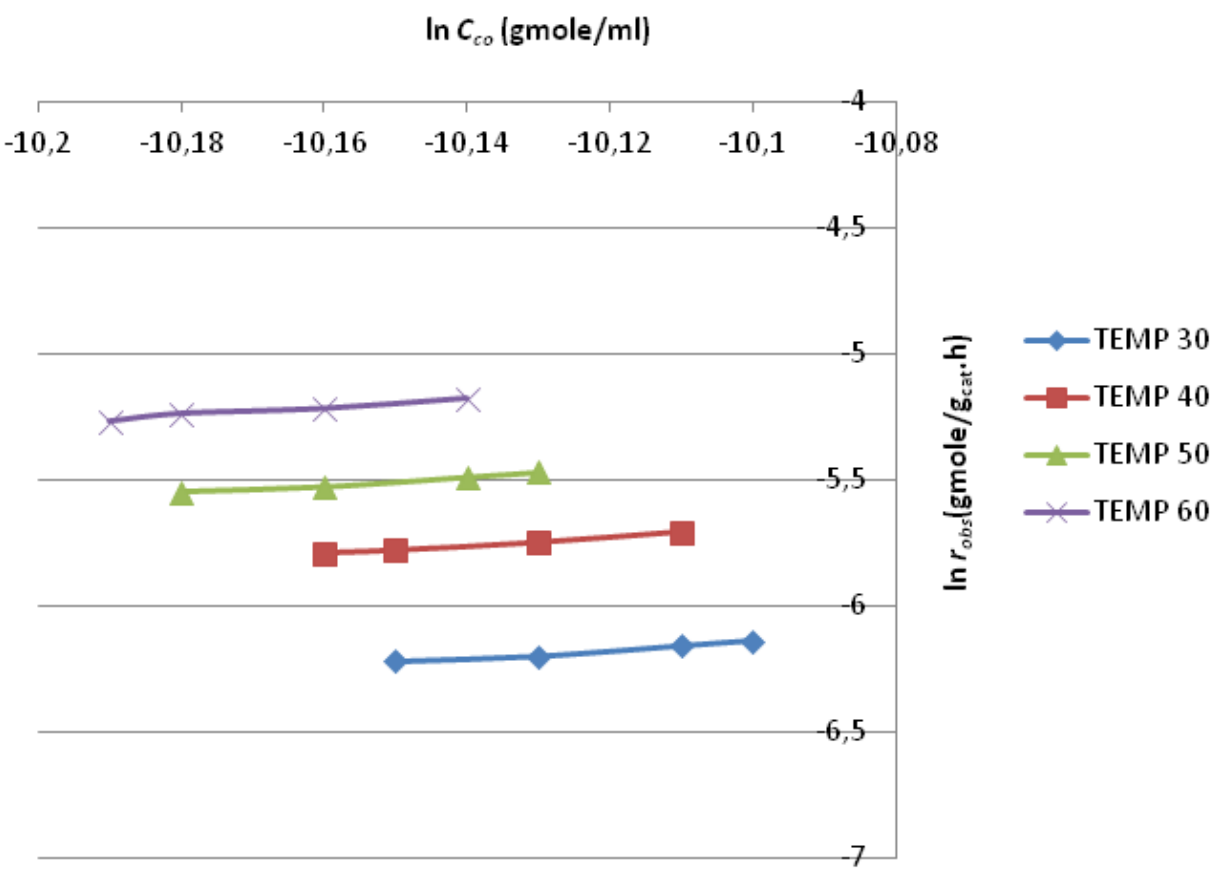

Figure 11. Plot of $\ln r_{o b s}$ vs. $\ln C_{c o}$ at different temperature $\left({ }^{\circ} \mathrm{C}\right)$ 


\subsubsection{Effect of The Space Velocity}

To study the effect of space velocity on conversion of $\mathrm{CO}$ activity of different catalyst were examined with increasing the space velocity. The temperature and feed composition were fixed. The effect of space velocity on CO conversion is shown below in Table 5 and 6 .

The Equation (2) can be obtained by performing material balance on $\mathrm{CO}$ in the reactor under steady state condition.

$$
r_{o b s}=\frac{d x_{C O}}{d\left(W / F_{C O}\right)}
$$

A series of experimental run in packed bed column was made using varying reciprocal weight hourly space velocity $\left(W / F_{C O}\right)$. The mass of the catalyst, $100 \mathrm{mg}$ diluted with $5 \mathrm{ml}$ of alumina was kept constant throughout the steady state experimental program. The external and internal mass transfer effects were absent during the experiment. The variation in $W / F_{C O}$ was achieved by changing the feed rate of $\mathrm{CO}$. To minimize the heat and mass transfer effect and to approximate differential reactor; conversion for each run was kept up to $10 \%$. The rate at any conversion can be obtained by taking the slope of $x_{C O}$ versus $W / F_{C O}$ plot.

Once the rate of reaction is known as a function of concentration of reactants, an empirical

Table 9. Order of the reaction

\begin{tabular}{ccccc}
\hline $\mathrm{T}(\mathrm{K})$ & 303 & 313 & 323 & 333 \\
\hline$m$ & 1.6727 & 1.610 & 1.627 & 1.687 \\
$\ln K$ & 10 & 10.48 & 11 & 11.83 \\
\hline
\end{tabular}

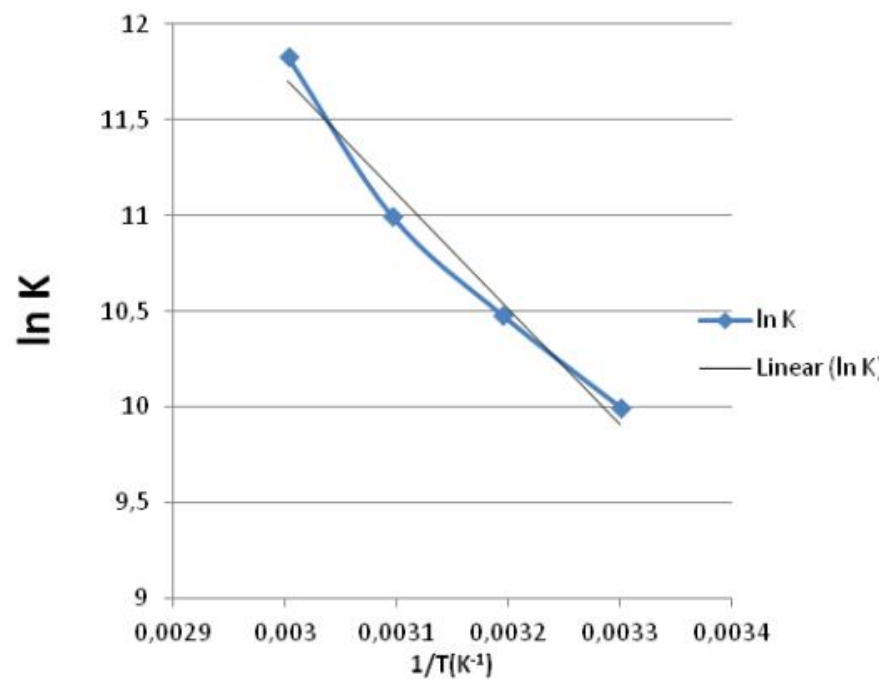

Figure 12. Arrhenius plot ln $K$ versus $1 / T\left(\mathrm{k}^{-1}\right)$ power law type of Equation (3) can be fitted:

$$
r_{\text {obs }}=k C_{\mathrm{O}_{2}}^{m} C_{C O}^{n}
$$

In the present study oxygen was in excess, therefore the rate expression reduces to Equation (4):

$$
r_{o b s}=k C_{C O}^{n}
$$

The $k$ is a function of temperature and can be represented by Arrhenius in Equation (5).

Taking natural log on both sides of the above equation, we get Equation (5) of straight line.

where:

$$
\ln (\text { rate })=\ln K+n \ln \left(C_{C O}\right)
$$

$$
K=A \exp (-E / R T)
$$

If the power law functionality is successful and $r$ versus $C_{C O}$ data are known at constant temperature, $n$ and $k$ at that temperature can be determined from log-log plot of $r_{o b s}$ versus $C_{C O}$.

Linear plot were obtained when $\ln r_{o b s}$ and ln $C_{C O}$ were plotted. Slope and intercept of the lines gives order of reaction and ln $k$, respectively. The reaction rate constant follows Arrhenius law. The activation energy of the reaction and frequency factor $A$ can be evaluated from the slope of a plot of $\ln k$ versus $1 / T$.

A plot of $\mathrm{CO}$ conversion to $\mathrm{CO}_{2}\left(x_{C O}\right)$, when the catalyst showed steady performance, versus $W / F_{C O}$ at four different temperatures is shown in Figure 10. Rate of reaction at different conversion for each temperature can be calculated by measuring the slope of the curve. The plot of $\ln r_{o b s}$ and $\ln c_{c o}$ gives the linear plot. The intercept and slope of this curve gives value of $\ln k$ and order of reaction, respectively. The slope and intercept of the Figure 11 gives order of reaction $(m)$ and $\ln K$, respectively. Slope and intercepts of the line give order of the reaction $(m)$ and $\ln K$ respectively, which are reported in Table 9. Order of the reaction was found to be 1.6. The activation energy $(E)$ and preexponential factor $(A)$ of Arrhenius equation were calculated by measuring the slope and intercept respectively of the plot of $\ln K$ versus $1 / T$ as shown in Figure 12. The values obtained are: (i). Activation energy $(\mathrm{E})=502.03$ $\mathrm{kJ}$ mole-1, (ii). Pre-exponential factor (A) = $9.1064 \times 10^{12}$. Rate of reaction as presented in Equation (7) was found in temperature range of 303- $333 \mathrm{~K}$.

Rate $=9.1064 \times 10^{12} \exp (502.03 / R T)\left(C_{C O}\right)^{1.6}$ 


\section{Conclusion}

The mole ratios of $\mathrm{Cu}$ :Co prepared by coprecipitation method have higher activity than the catalyst prepared by wet impregnation and sol gel methods. The catalyst were calcined at $400{ }^{\circ} \mathrm{C}$ and activity was observed for $\mathrm{CO}$ oxidation it was seen that each catalyst containing $\mathrm{Cu}$ :Co of 1:4 have higher activity. The catalytic test shows that the mole ratio of $\mathrm{Cu}$ :Co of $1: 4$ exhibits the highest activity towards $\mathrm{CO}$ oxidation at lowest temperature $110^{\circ} \mathrm{C}$. The best activity of the prepared 1:4 catalyst calcined at $400^{\circ} \mathrm{C}$.

The kinetic study was done by taking the catalyst having mole ratio of $\mathrm{Cu}: \mathrm{Co}$ of $1: 4$. This was prepared by co-precipitation method. Effect of space velocity was observed at four different temperatures. The rate was obtained by taking the slope of $x_{C O}$ versus $W / F_{C O}$ plot. On the basis of experimental finding the order of reaction was observed 1.6 and the rate equation was found expressed as in Equation (7).

\section{References}

[1] Bamwenda, G., Tsubota, S., nakamura, T., and Haruta, M. (1997). The influence of the preparation methods on the catalytic activity of platinum and gold supported on $\mathrm{TiO}_{2}$ for CO oxidation. Catalysis Letter, 44: 83-87.

[2] Oran, U., Uner, D. (2004). Mechanisms of CO oxidation reaction and effect of chlorine ions on the $\mathrm{CO}$ oxidation reaction over $\mathrm{Pt} / \mathrm{CeO}_{2}$ and $\mathrm{Pt} / \mathrm{CeO}_{2} / \mathrm{\gamma}-\mathrm{Al}_{2} \mathrm{O}_{3}$ catalysts. Applied $\mathrm{Ca}$ talysis B: Environment, 54: 183-191.

[3] Liu, Z.P., Hu, P. (2002). Catalytic role of gold in gold based catalyst: a density functional theory study on the CO oxidation on the gold. Journal of American Chemical Society, 124: 14770-14779.

[4] Lopez, N., Janssens, T.V.W., Clausen, B.S., $\mathrm{Xu}$, Y., Maverikakis, M., Bligaard, T., Norskov, J.K. (2004). On the origin of catalytic activity of gold nanoparticles for lowtemperature oxidation. Journal of Catalysis, 223: 232-235.

[5] Rossignol, C., Arrii, S., Morfin, F., Piccolo, L., Caps, V., Rousset, J.L. (2005). Selective oxidation of $\mathrm{CO}$ over model gold based catalyst in the presence of $\mathrm{H}_{2}$. Journal of Catalysis, 230: 476-483.

[6] Rao, K.N., Bharali, P., Thrimurthulu, G., Reddy, B.M. (2010). Supported copper-ceria catalysts for low temperature CO oxidation. Catalysis Communications, 11: 863-866.

[7] Stoyanova, D., Christova, M., Dimitrova, P., Marinova, J., Kasabova, N., Panayotov, D. (1998). Copper Cobalt oxide spinel supported on high-temperature aluminosilicate carriers as catalyst for $\mathrm{CO}-\mathrm{O}_{2}$ and $\mathrm{CO}-\mathrm{NO}$ reactions. Applied Catalysis B: Environmental, 17: 233244.

[8] Eyubova, S.M., Yagodovskii, V.D. (2007). The oxidation of carbon monoxide on a catalyst with a spinel structure containing $\mathrm{Mg}$ Ferrite. Russian Journal of Physical and Chemistry A, 81: 544-548.

[9] Mokhtar, M., Basahel, S.N., Al-Angary, Y.O. (2010). Nanosized spinel oxide catalysts for $\mathrm{CO}$-oxidation prepared via $\mathrm{CoMnMgAl}$ quaternary hydrotalcite route. Journal of Alloys and Compounds, 493: 376-384.

[10] Wu, G., Guan, N., Li, L. (2011). Low temperature $\mathrm{CO}$ oxidation on $\mathrm{Cu}-\mathrm{Cu}_{2} \mathrm{O} / \mathrm{TiO}_{2}$ catalyst prepared by photodeposition. Catalysis Science and Technology, 1: 601-608.

[11] Zhu, J., Gao, Q. (2009). Mesoporous $\mathrm{MCo}_{2} \mathrm{O}_{4}$ $(\mathrm{M}=\mathrm{Cu}, \mathrm{Mn}$ and $\mathrm{Ni}$ ) spinels: Structural replication, characterization and catalytic application in $\mathrm{CO}$ oxidation. Microporous and Mesoporous Mterials, 124: 144-152.

[12] Xia, C., Junfeng, Z., Yan, H., Zhiquan, T., Ming, H. (2009). Catalytic reduction of nitric oxide with carbon monoxide on copper-cobalt oxides supporeted on nano-titanium dioxide. Journal of Environmental Sciences, 21: 12961301.

[13] Wojciechowska, M., Przystajko, W., Zielin, M. (2007). CO oxidation catalysts based on copper and manganese or cobalt oxides supported on $\mathrm{MgF}_{2}$ and $\mathrm{Al}_{2} \mathrm{O}_{3}$. Catalysis Today: 119: 338-341.

[14] Kang, M., Song, M.W., Lee, C.H. (2003). Catalytic carbon monoxide oxidation over $\mathrm{CoO}_{\mathrm{x}} / \mathrm{CeO}_{2}$ composite catalysts. Applied Catalyst A: General, 251: 143-156.

[15] Zhang, Y.X., Guo, X., Zhai, X., Yan, Y.M., Sun, K.N. (2015). Diethylene assited anchoring of $\mathrm{Co}_{3} \mathrm{O}_{4}$ nanorods on carbon nanotubes as efficient electrocataysts for the oxygen evolution reaction. Journal of Materials Chemistry A, 3: 1761.

[16] Zhao, Z., Yung, M.M., Ozkan, U.S. (2008). Effect of support on the preferential oxidation of $\mathrm{CO}$ over cobalt catalysts. Catalysis Communications, 9: 1465-1471.

[17] Yung, M.M., Holmgreen, E.M., Ozkan, U.S. (2007). Low- temperature oxidation of Carbon monoxide on $\mathrm{Co} / \mathrm{ZrO}_{2}$. Catalysis Letter, 118: 180-186.

[18] Li, G., Lia, L., Shi, J., Yuan, Y., Lia, Y., Zhao, W., Shi, J. (2014). One -pot pyrolytic synthesis of Mesoporous $\mathrm{MCo}_{2} \mathrm{O}_{4(4.5)}(\mathrm{M}=\mathrm{Mn}, \mathrm{Ni}, \mathrm{Fe}$, $\mathrm{Cu}$ ) spinels and its high efficient catalytic properties for $\mathrm{CO}$ oxidation at low temperature. Journal of Molecular Catalysis A: Chemical, 390: 97-104. 
[19] Kramer, M., Schmidt, T., Stowe, K., Maier, W.F. (2006). Structural and catalytic aspects of sol-gel derived copper manganese oxides as low temperature $\mathrm{CO}$ oxidation catalyst. $A p$ plied Catalysis A: General, 302: 257-263.

[20] Wang, C.B., Tang, C.W., Tsai, W.C., Kuo, M.C., Chien, S.H. (2006). In situ FTIR spectroscopic studies on the mechanism of the catalytic oxidation of carbon monoxide over supported cobalt catalysts. Catalysis Letter, 107: 31-37.
[21] Rattan, G., Kumar, M. (2014). Carbon monoxide oxidation using cobalt catalysts: A short review. Chemistry and Chemical Technology, 8(3): 249-260.

[22] Rattan, G., Prasad, R., Katyal, R.C. (2012). Effect of Preparation Methods on $\mathrm{Al}_{2} \mathrm{O}_{3}$ Supported $\mathrm{CuO}-\mathrm{CeO}_{2}-\mathrm{ZrO}_{2}$ Catalysts for $\mathrm{CO} \mathrm{Oxi}-$ dation. Bulletin of Chemical Reaction Engineering \& Catalysis, 7(2): 112-123, doi: 10.9767/bcrec.7.2.3646.112-123. 